\title{
Simulation Study for Controlling Direct Current Motor Position Utilising Fuzzy Logic Controller
}

\author{
N. Elias* and N. M. Yahya \\ Faculty of Manufacturing Engineering, Universiti Malaysia Pahang, \\ 26600 Pekan, Pahang, Malaysia \\ *Email: nurainaa_elias@yahoo.com \\ Phone: +601397972754; Fax: +6094245888
}

\begin{abstract}
A fuzzy logic controller (FLC) modelled with MATLAB toolbox that is implemented for position control of a direct current (DC) motor is presented in this paper. The position control is an adaptation of an assisted lifting device system. Due to the existing assisted lifting device problems that lift the load slowly and having lack of accuracy, this research is conducted to improve current assisted lifting device with the introduction of a DC motor and a fuzzy logic controller (FLC) that can improve position accuracy, especially when loading the loads. The DC motor was modelled, converted to a subsystem in Simulink and then the MATLAB toolbox is used to design the FLC. The methodology covers the simulation and modelling of the DC motor, fuzzy logic controller and different transfer functions for DC motor model as a benchmark to the performance of the fuzzy system. The outcomes acquired from the scope of the simulation was analysed. Parameters such as the rise and settling time in seconds and maximum overshoot in percentage are observed to be compared with different types of transfer functions that are used for the dynamic response of the closed-loop system and system with and without a controller that was used as references. The overall performance shows that a system with FLC performs well compared to the system without FLC.
\end{abstract}

Keywords: Fuzzy logic; position control; DC motor; transfer function; Simulink.

\section{INTRODUCTION}

The electric device that converts electrical energy into mechanical energy is known as electric motor. Alternating Current (AC) sources such as generators, power grid, or inverters, or Direct Current (DC) sources, such as from rectifiers and batteries are used for the functioning of the electric motor [1]. A DC motor has been selected as the platform to do the experiment because the position and speed are needed especially in electronic devices, manufacturing applications, and automated utilisation. The DC motor can be controlled by a wide range of devices, making DC motor application development relatively accessible and flexible. It also has speed variation and torque [1]. DC motor may be a brushed or brushless, but brushless DC motor is chosen in this study because current, voltage, torque and rpm are linearly related. Other than that, the brushless DC motor can eliminate ionizing sparks, has a long operating life and noiseless operation, as well as high in efficiency and speed ranges [2].

The range for simulating the study is by mimicking the position control of the assisted lifting device. With advances in computational capability, sensing and also control technology, assisted lifting device is introduced to eliminate these highly 
repetitive lifting of heavy awkward loads and unnatural motions [3]. Assisted lifting devices are increasingly being used around the world to assist industrial workers especially in material handling system (MHS) environments [4]. The assisted lifting devices address the need for a solution that bridges the limitation of conventional MHS and the high capital costs of robots in industrial environments. The most typical kinds of assisted lifting device that is used to lift loads on an adjustable height thus reducing the risk of a repetitive stress injury and bringing the loads into the power zone are hydraulic lift tables, pneumatic lift tables, and ball screw lift tables [5]. Pneumatic lift tables are powered by an air compressor to transport goods for ease of loading and unloading [6]. It usually uses several kinds of airbag; either one, two, or multiple relying upon the capacity and its application. The pneumatic lift tables are commonly applied in light-duty operations with lower maximum capacity, where a large vertical lift is required, or if the exact placement is demanded [6]. The ball screw scissor lift table requires an electric motor that shifts a horizontal or vertical ball screw that mobilises the scissors and platform up and down [7]. Hydraulic lift tables which are most widely available in the market are known to adjust the height of an object to enable a standing person to easily handle the object. The lifting table includes bottom and top platforms with a scissors link mechanism connecting with the straight movement whether upward or downward of the top platform $[8]$.

The hydraulic lift table functions when pressurised hydraulic fluids power a linear actuator to raise the table. Therefore, an accompanying hydraulic pump is required. A hydraulic cylinder activates the lift platform inserted in the centre of a pair of parallel shafts located at the upper and lower part. The lift table offers the mechanical upward and downward motion in a vertical plane [9]. The lift table brings the loads closer to the worker and thus reduces reaching and back flexion. However, in operations that demand accurate and exact positioning despite the load, the hydraulic lift tables are either awkward to move at the needed height or have too much "bounce" when loads are being altered or switched [10]. Besides that, there is also a 3-axis assisted device that is capable to guide human motions via virtual surfaces. Virtual surfaces are like rulers, userprogrammable and multi-dimensional [11]. The multi-axes (x, y, and $\mathrm{z}$ ) use a servooperated trolley to move the assisted lifting device. Therefore, the workers should be designated in which direction the loads are moving and then the system will provide force to speed up and slow down the device [11]. Either one or two axes could be powered, as needed. However, the time needed to speed up and slow down the assisted lifting device increases the cycle times, especially when accurate positioning is demanded [12]. Besides that, the device collisions are a major problem when the device is powered by the actuator because the worker needs to operate the device at a higher speed. The classical repulsive algorithm to avoid collisions was discovered to be unstable in the multi-axis lifting device [13]. Other than that, a Four-Degree of Freedom (DOF) heavy-lift assist device is one of the existing assisted lifting devices. The elbow, base, and wrist DOF are powered by DC servomotors to reduce the physical labour required by the operator while operating the device. Closed loop control is applied to operate the manipulator [14]. Multi-axis motion control board is used to direct the servomotors. But, due to the controller problem, the position of the lift assist device is not accurate. The time delays, nonlinearities and high orders make it difficult to tune the PID gains properly.

While such existing lifting table performs quite satisfactorily, a more ergonomic and intelligent alternative is frequently needed. Hydraulic lift table is chosen compared to other assisted lifting device because of the stability and simple to assemble [15]. The existing hydraulic lift table still lifts slowly especially during the loading process [16]. 
The hydraulic lift table also lifts slowly when a weightier load is placed on it. Some of the lift tables also did not lift the right adjusting height. So, due to the existing hydraulic lift table problems that lift the load slowly and not having position accuracy, this research is done to improve the existing hydraulic lift table with an introduction of the fuzzy logic controller (FLC) into the DC motor that can boost speed and also improve position accuracy, especially when loading the loads. By using the controller, the position can be adjusted until it gets like the desired output that user needs. Fuzzy logic is reviewed as the substitute for typical control theory in the complex nonlinear plants in control system since the exact mathematical modelling is hard and problematic [17]. The mathematical modelling is unnecessary for designing of the controller because it is one of the superior features of fuzzy logic compared to the traditional control approach. The control rules are stationed fundamentally on knowledge of the system behaviour and the experience of the control engineer. Considering that the fuzzy logic controller demands simple mathematical works compared to other classical controllers, its application needed lowspeed processors.

Therefore, for this research, MATLAB/Simulink is chosen as a platform to simulate and design the fuzzy logic controller. The simulation of a different model of DC motor is part of this study so that it differentiated based on the performance. The novelty of this research compared to others is that the fuzzy logic controller designed is compared with different types of transfer function for the DC motor, and the controller uses the centroid method to be optimised.

\section{MATERIAL AND METHOD}

In order to achieve the research objective, the flow of work must be planned. The research methodology can be divided into 2 phases. The first phase involved the design of the fuzzy logic controller (FLC). The second phase is the simulation of proposed FLC on DC motor position control. The results of the simulations are elaborate and discussed in the Result section. The types of response that are considered is the response to sudden load increment and also decrement.

\section{Fuzzy Logic Controller}

A fuzzy logic controller (FLC) has four crucial elements that need to be implemented, namely fuzzification, inference mechanism, rule base and defuzzification [18]. The controller functioning and also membership function structure plays an important role as the number of fuzzy sets that establish linguistic variables, mapping of the measurements onto the support sets and regulation of protocol. Thus, the tuning of FLC can be done by altering the parameters and also replacing the membership functions or the designing rules [19]. The FLC is designed in the Matlab toolbox and then was called back in the Simulink. The name of the FLC that is built in the Matlab toolbox must be the same as in the Simulink.

Fuzzy logic controller (FLC) is an example of control methods known as the multi-rule-based variable's consideration. This method gives quicker outcomes when comparing to other traditional and conventional control methods such as ProportionalIntegral-Derivative (PID) and Neural Networks. Being nimble and steadfast are the main reasons for selecting FLC in controlling the intent in the recent study. Compared to any other controller, FLC required some inputs to develop some control signal. For this research, there are two inputs and one output. The inputs of FLC, namely an error (e) and 
change of error (ce), are selected based on the variances in position. The parameters chosen is based on the minimisation of error for the input so that the reference's value that was inserted can be plus or minus in getting more accurate position, and also to improve robustness of the overall system. Equations (1) and (2) indicate the selected inputs for the FLC system.

$$
\begin{aligned}
& e(t)=\frac{w_{\text {ref }}-W_{\text {measured }}}{w_{\text {ref }}} \\
& \text { ce }(t)=\frac{\Delta e(t)}{\Delta t}=e(t)-e(t-1)
\end{aligned}
$$

To implement the FLC in a problem, different steps of this rule based must be taken as follows:

i. Fuzzification: The input constructed in the Matlab toolbox needed to be fuzzified by the membership functions. The membership function gives a value of $\mu$ to each of the input values. The centroid method was picked for building the required triangle type of the membership function. The variables for input and output for the FLC consist of seven fuzzy sets, namely NL (negative large), NM (negative medium), NS (negative small), ZE (zero), PS (positive small), PM (positive medium) and PL (positive large).

ii. Inference diagram: According to Mamdani [18], the rule base should be tested into the membership function that has been achieved. The rule table is tabulated and shown in Table 1. The surface viewer also can be attained when MATLAB FLC Inference is applied.

Table 1. Rules table of the fuzzy logic controller.

\begin{tabular}{cccccccc}
\hline \multirow{2}{*}{$c e$} & & & & $\Delta \mathrm{e}$ & & & \\
& $\mathrm{NL}$ & $\mathrm{NM}$ & $\mathrm{NS}$ & $\mathrm{ZE}$ & $\mathrm{PS}$ & $\mathrm{PM}$ & $\mathrm{PL}$ \\
\hline NL & NL & NL & NL & NL & NM & NS & ZE \\
NM & NL & NL & NL & NM & NS & ZE & PS \\
NS & NL & NL & NM & NS & ZE & PS & PM \\
ZE & NL & NM & NS & ZE & PS & PM & PL \\
PS & NM & NS & ZE & PS & PM & PL & PL \\
PM & NS & ZE & PS & PM & PL & PL & PL \\
PL & ZE & PS & PM & PL & PL & PL & PL \\
\hline
\end{tabular}

\section{Motor Model}

A DC motor is generally adopted in the control system process due to advantages such as preciseness, smooth application, faster adaption, electrically efficient and high-power density [20]. DC motors are superb for many adjustable position controls and also purposely applied in a broad area of position drivers. A superb position control system makes the DC motor applicable in adjustable position variations, for example in this study as assisted lifting devices that are mostly used in the manufacturing industry. The DC motor is designed using the Simulink block diagram. 
For this study, three different transfer functions are used for representing the motor model. The main reasons for the difference are the model of DC motor and also the parameter that is used. In armature control of separately excited DC motors, the voltage used for the motor armature is adjusted without changing the voltage applied to the field. Figure 1 shows the same model of a separately excited DC motor.

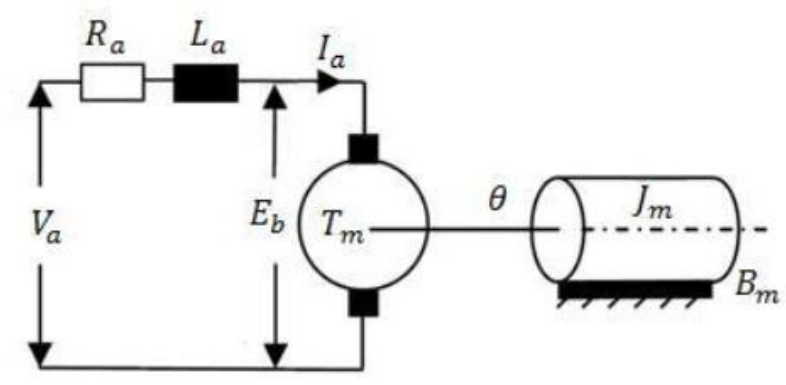

Figure 1. DC motor model.

The relation between rotor shaft speed and applied armature voltage is represented by the transfer function:

$$
\frac{W(s)}{V_{a}(s)}=\frac{K_{T}}{L_{a} \cdot J_{m} \cdot s^{2}+\left(R_{a} \cdot J_{m}+L_{a} \cdot B_{m}\right) \cdot s+\left(R_{a} \cdot B_{m}+K_{b} \cdot K_{T}\right)}
$$

The relation between position and speed is given in Eq. (4). Then the transfer function between shaft position and armature voltage at no load is in Eq. (5).

$$
\begin{aligned}
& \theta(\mathrm{s})=\frac{1}{\mathrm{~s}} \mathrm{~W}(\mathrm{~s}) \\
& \frac{\theta(\mathrm{s})}{\mathrm{V}_{\mathrm{a}}(\mathrm{s})}=\frac{\mathrm{K}_{\mathrm{T}}}{\mathrm{L}_{\mathrm{a}} \cdot \mathrm{J}_{\mathrm{m}} \cdot \mathrm{s}^{3}+\left(\mathrm{R}_{\mathrm{a}} \cdot \mathrm{J}_{\mathrm{m}}+\mathrm{L}_{\mathrm{a}} \cdot \mathrm{B}_{\mathrm{m}}\right) \cdot \mathrm{s}^{2}+\left(\mathrm{K}_{\mathrm{T}} \cdot \mathrm{K}_{\mathrm{b}}+\mathrm{R}_{\mathrm{a}} \cdot \mathrm{B}_{\mathrm{m}}\right) \cdot \mathrm{s}}
\end{aligned}
$$

where $\mathrm{v}_{\mathrm{a}}=$ armature voltage $(\mathrm{V}), \mathrm{R}_{\mathrm{a}}=$ armature resistance $(\Omega), \mathrm{L}_{\mathrm{a}}=$ armature inductance $(\mathrm{H}), \mathrm{I}_{\mathrm{a}}=\operatorname{armature}$ current $(\mathrm{A}), \mathrm{E}_{\mathrm{b}}=\operatorname{back} \operatorname{emf}(\mathrm{V}), \mathrm{w}=$ angular speed $(\mathrm{rad} / \mathrm{s}), \mathrm{T}_{\mathrm{m}}=$ motor torque $(\mathrm{Nm}),{ }^{\theta}=$ angular position of rotor shaft $(\mathrm{rad}), \mathrm{J}_{\mathrm{m}}=$ rotor inertia $\left(\mathrm{kgm}^{2}\right), \mathrm{B}_{\mathrm{m}}=$ viscous friction coefficient $(\mathrm{Nms} / \mathrm{rad}), \mathrm{K}_{\mathrm{T}}=$ torque constant $(\mathrm{Nm} / \mathrm{A})$ and $\mathrm{K}_{\mathrm{b}}=$ back emf constant (Vs/rad).

\section{RESULTS AND DISCUSSION}

When the fuzzy logic controller is fully constructed, and a 3D input-output is achieved from the Surface Viewer, the MATLAB Simulink model has been built for simulating the fuzzy logic controller and evaluating the performance of the system. The rules that set in the fuzzy logic controller act as a "brain" - controller for the whole system. The performance of the designed system was simulated throughout the output Scope of the Simulink model. The fuzzy logic controller blocks existed in MATLAB Simulink Library. The output actuator in the Simulink model used was the DC motor. The DC motor transfer function that is used in the Simulink model represents the output actuators. 
The result from scope were compared either by using the controller or without the controller for both transfer functions. The first transfer function was in 1-in 1-out subsystem while for the other transfer function was 2-in 2-out subsystem used for the DC motor position control. Finally, the transfer function that is mostly used for the DC motor was simulated.

\section{1-in 1-out Subsystem}

The performance of the system was evaluated by the simulation results from MATLAB Fuzzy Logic Toolbox and MATLAB Simulink. For the first block diagram, a 1-in 1-out subsystem is used for the DC motor block diagram. The system is named as Motor_pos1 as shown in Figure 2. The input is the voltage while the output is the position of the DC motor for the DC motor block diagram. The voltage was converted to the output position by adding the value of inductance and resistance integrated into the final value.

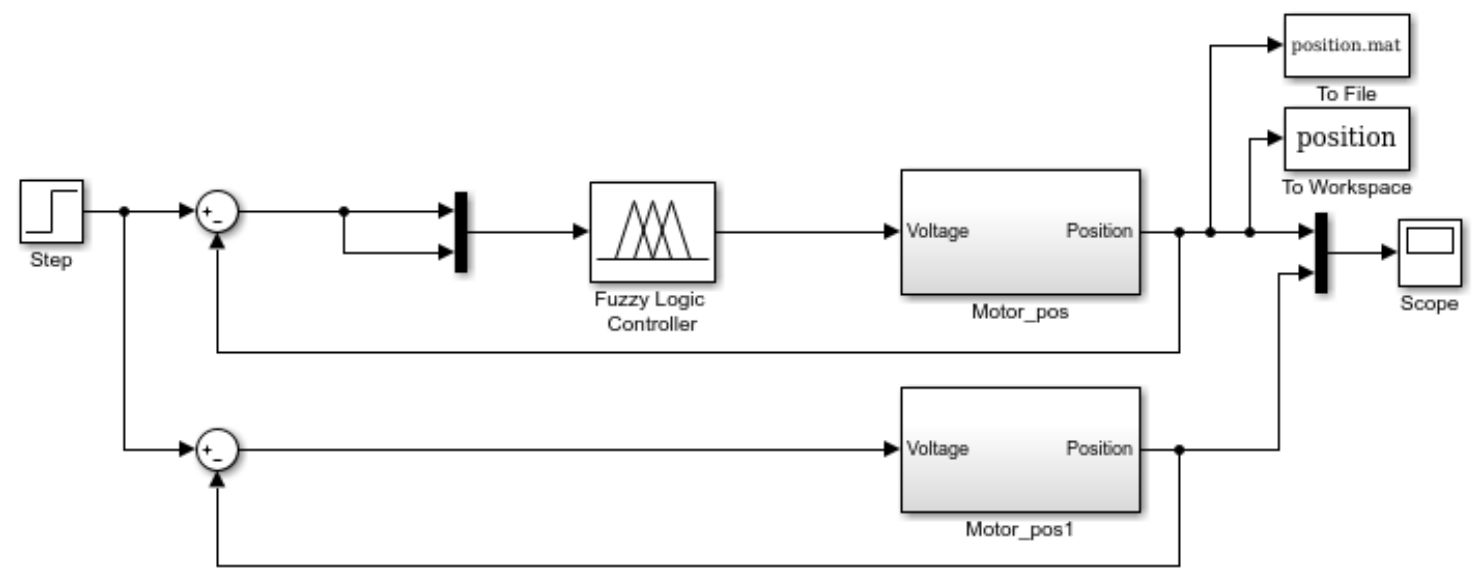

Figure 2. Block diagram for the DC motor model for the 1-in 1-out subsystem.

The Simulink model that is shown in Figure 2 consists of the controller that has been designed and the DC motor position block function. The output from the DC motor block which is the motor position is monitored using a 'Scope' to analyse its response. The same Simulink model is used for transfer function without using the controller. The result from the scope is shown in Figure 3. From the scope, the line graph of the system without the controller is slower compared to the system that used the controller. The dotted line represents the reference point and the straight line from the graph represents the simulated point in which the controller has been implemented in the DC motor. The straight line can be seen clearly that it has a faster response in term of rising time and quickly becoming stable compared to the dotted line that represents the system without using the controller. 


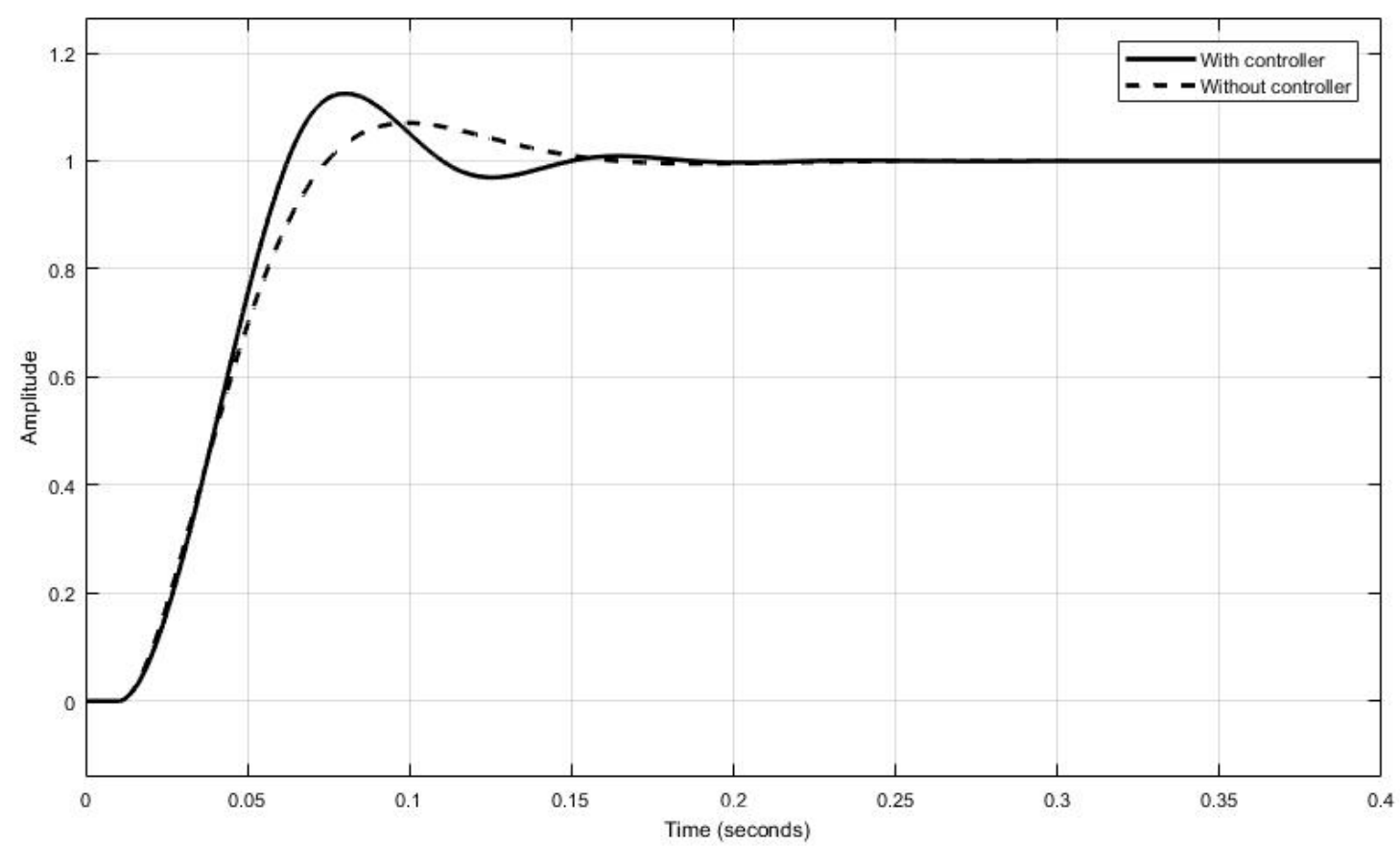

Figure 3. Step response results for Simulink model without and with a fuzzy logic controller.

\section{2-in 2-out Subsystem}

For the second block diagram, a 2-in 2-out subsystem is used for the DC motor block diagram. The system is named as DC Motor as shown in Figure 4. The input ports were armature voltage, Va, and load torque, Tload, while the output ports are angular speed, w, and position , $\theta$. For the load torque, the value is zero since the response for the speed was ignored because the aim for the research is only to get the response from the position.

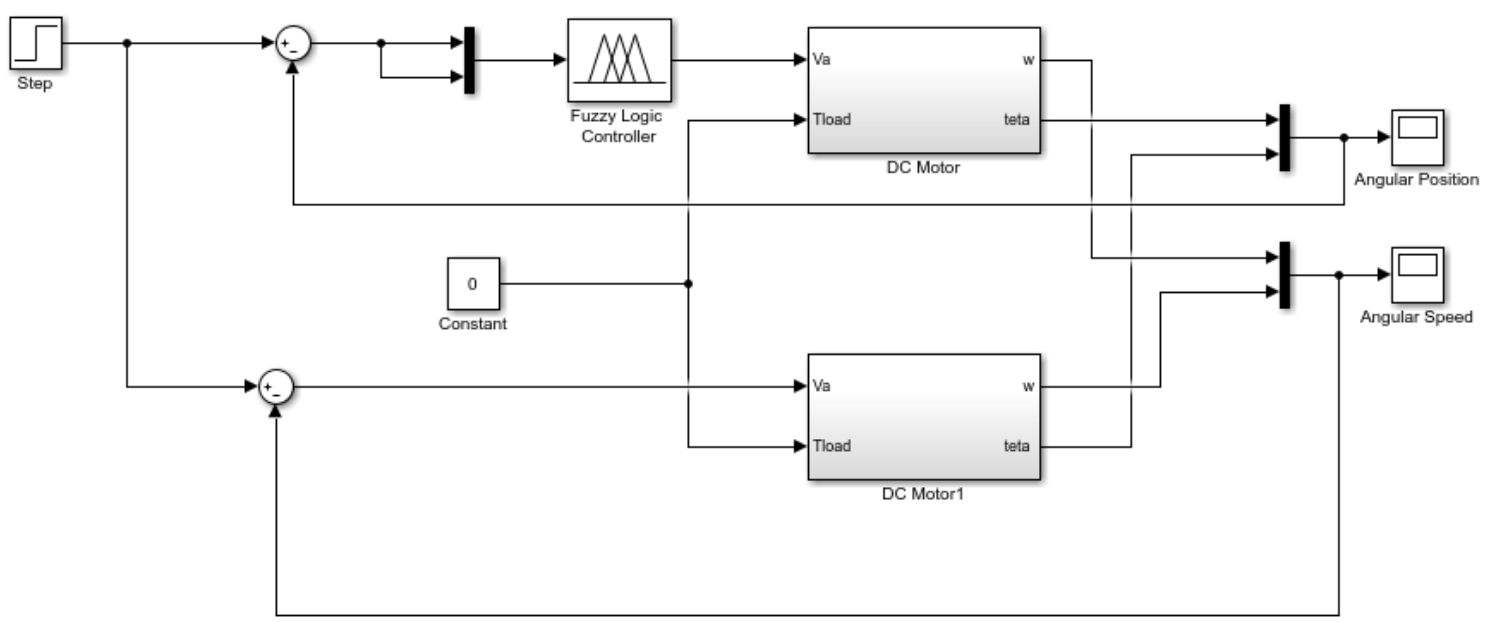

Figure 4. Block diagram for the DC motor model for the 2-in 2-out subsystem.

The results for the step response for the Simulink model that used 2-in 2-out subsystem is shown in Figure 5. The dotted line from the graph represents the reference 
point while the straight line is the desired point which is the DC motor that has been implemented with the fuzzy logic controller. The amplitude for the dotted line is bigger compared to the amplitude in the straight line of the graph. Therefore, the curve of the dotted line is less steep compared to the curve in the straight-line graph. The steeper the graph means that the rise time is faster compared to the less steep one. The obtained result is important since it clearly shows that the system without the controller that is represented by dotted line has less response compared to the system that used the controller which is represented by the straight line.

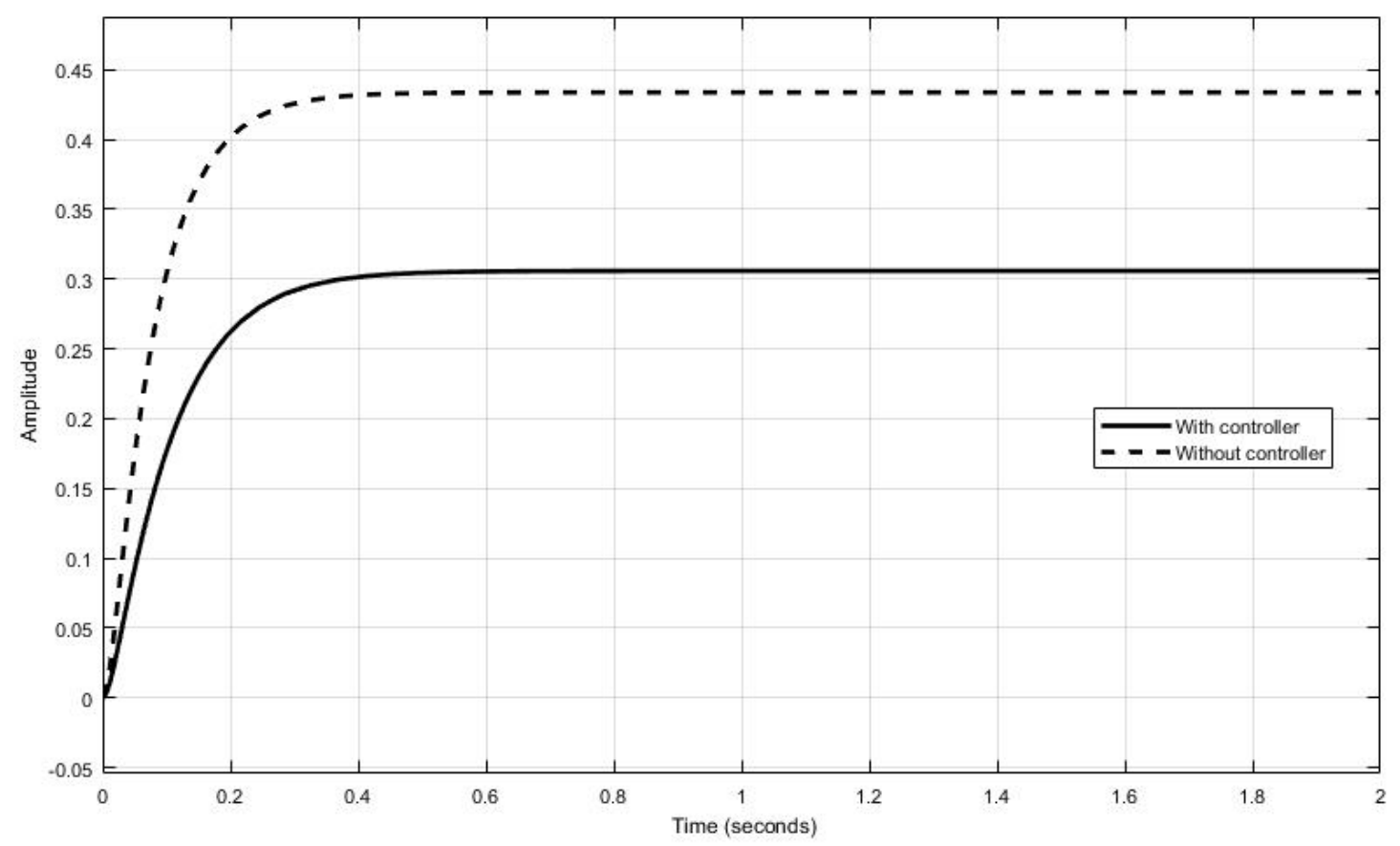

Figure 5. Step response results for Simulink model without and with a fuzzy logic controller

\section{Typical Type of DC Motor Transfer Function}

For the third block diagram, a commonly used transfer function for the DC motor block diagram is chosen. The system is named as DC Position Motor as shown in Figure 6. The motor parameters in the transfer function are achieved from the armature resistance, armature inductance, torque constant, and rotor inertia of the typical brushless DC motor A2208. All values are obtained from the product specifications of the brushless DC motor.

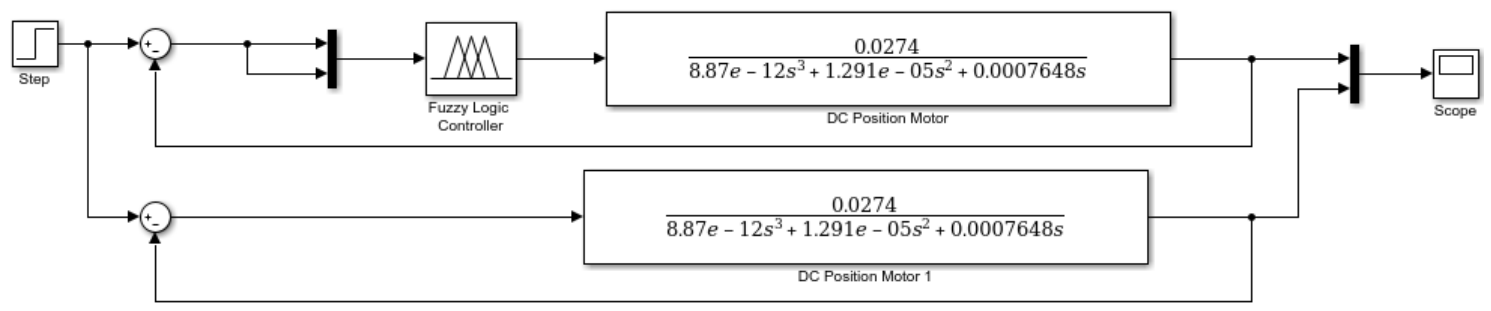

Figure 6. Block diagram for the DC motor model for the typical brushless DC motor 
The results for the step response for the Simulink model that used a typical DC motor is shown in Figure 7. The dotted line from the graph represents the reference point while the straight line is the desired point in which the DC motor has been implemented with a fuzzy logic controller. The line that represents the system that used the controller becomes faster in stationary state compared to the dotted line that represents the system without using the controller. Although there is an overshoot in the system that used the controller, the time to raise the response is faster compared to the system without the controller.

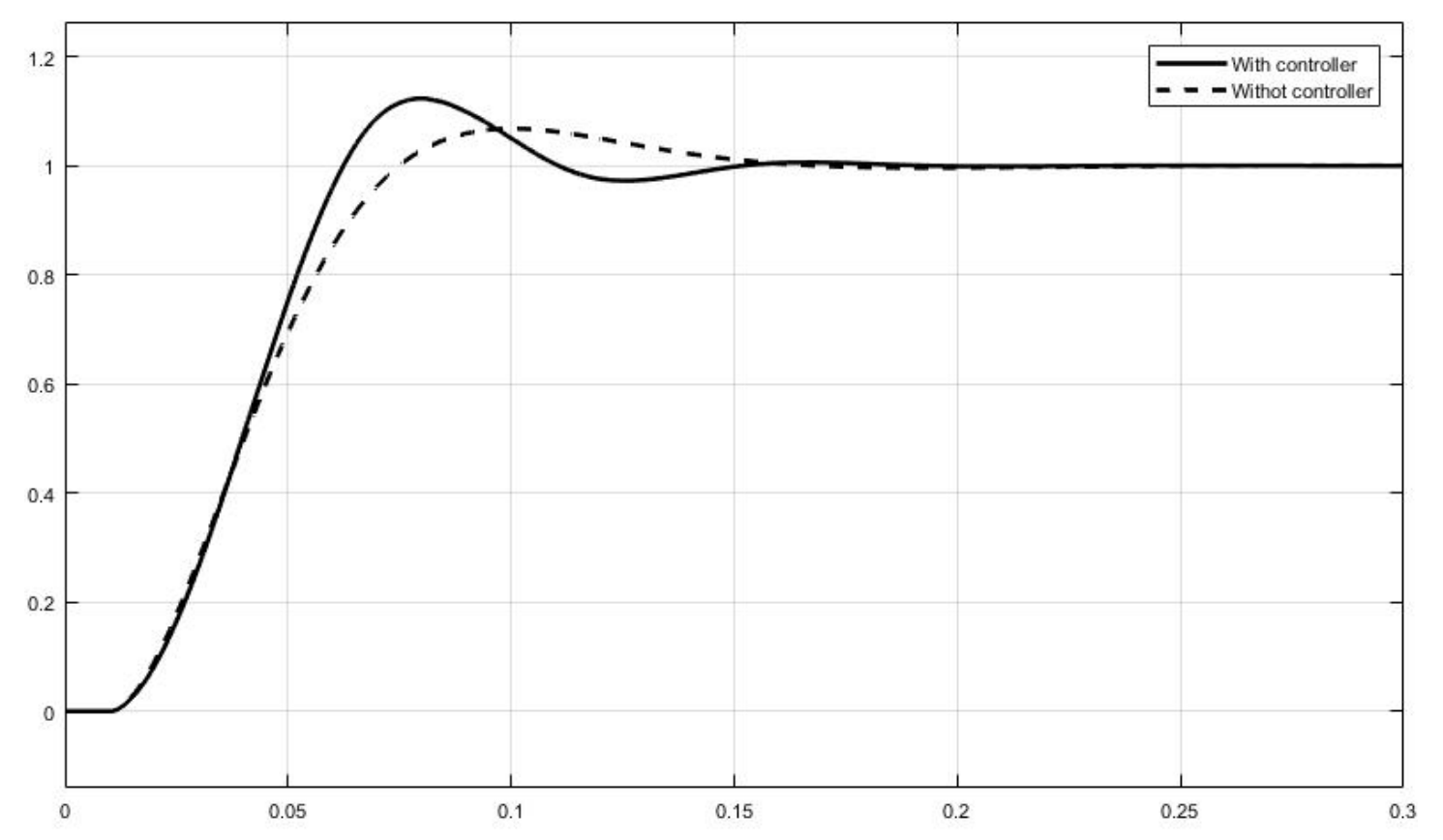

Figure 7. Step response results for Simulink model without and with a fuzzy logic controller.

\section{Comparative Results}

The simulated results were interpreted as shown in Table 2. The values of the response parameters such as rise time, settling time and percentage overshoot are tabulated. The simulation results show that the subsystems that used fuzzy logic controller have faster response than the system without a controller, which was expected. However, the system without a controller works better than the system that used a controller in terms of having lower overshoot. Since overshoot is important to achieve better rising time and speed up the performance, the value is neglected. The most important part to be observed is the rise time and the settling time. For the three different transfer functions of the DC motor position control block, the values of rising time and settling time for the system using the fuzzy logic controller is less compared to the system that does not use the controller. Conclusively, the fuzzy logic controller reduced rise time, increased the overshoot and decreased the settling time by a small amount. 
Table 2. Simulation results comparison.

\begin{tabular}{lcccccc}
\hline Metrics & 1-in 1-out subsystem & \multicolumn{2}{c}{ 2-in 2-out subsystem } & \multicolumn{2}{c}{ A typical DC motor } \\
Controller & $\begin{array}{c}\text { Without } \\
\text { controller }\end{array}$ & $\begin{array}{c}\text { Fuzzy } \\
\text { logic } \\
\text { controller }\end{array}$ & $\begin{array}{c}\text { Without } \\
\text { controller }\end{array}$ & $\begin{array}{c}\text { Fuzzy } \\
\text { logic } \\
\text { controller }\end{array}$ & $\begin{array}{c}\text { Without } \\
\text { controller }\end{array}$ & $\begin{array}{c}\text { Fuzzy } \\
\text { logic } \\
\text { controller }\end{array}$ \\
\hline $\begin{array}{l}\text { Rise time } \\
\text { (s) }\end{array}$ & 0.07 & 0.05 & 0.13 & 0.11 & 0.07 & 0.06 \\
$\begin{array}{l}\text { Settling } \\
\text { time (s) }\end{array}$ & 0.19 & 0.17 & 0.60 & 0.50 & 0.19 & 0.16 \\
$\begin{array}{l}\text { Overshoot } \\
(\%)\end{array}$ & 0.08 & 0.20 & 0 & 0 & 0.1 & 0.20 \\
\hline
\end{tabular}

\section{CONCLUSION}

The objective of this study was achieved as the fuzzy logic controller (FLC) that was designed performed well depending on the demand from a user (fuzzy rules) and can be simulated for different types of transfer functions. For the 1-in 1-out subsystem and typical DC motor transfer function, although the percentage of overshoot is higher, the time of rising and settling that represents the system with the fuzzy logic controller is faster compared with the one without using the controller. The overall performance in rising time, settling time and having no overshoot for the 2-in 2-out subsystem is better for the system using the controller compared to the system without using the controller. The output actuators motor's position with a fuzzy logic controller is accomplished with good performance, steady and precise as the desired set point compared to the system without using the fuzzy logic controller. Despite the better performance achieved, there are still some improvements that can be done to obtain better results. For this reason, some recommendations are added to establish better results and improve future works. An experimental work which includes a controller's prototype in a real condition for assisted lifting device should be developed. The limitation of this study is not having real data analysis for the DC motor position control for assisted lifting devices. Thus, it is recommended that future work be done combining simulation and actual experiments to achieve better results.

\section{ACKNOWLEDGEMENT}

This research is funded by the University Malaysia Pahang under research grant RDU180386. The authors would like to thank University Malaysia Pahang for encouraging this research.

\section{REFERENCES}

[1] Namzov M, Basturk O. DC motor position control using fuzzy proportionalderivative controllers with different defuzzification method. Official Journal of Turkish Fuzzy System Association 2010; 1(1): 36-54.

[2] Nasser T. Design and Applications of Fuzzy Logic for the Speed Control of a Direct-Drive DC Motor. In: 4th International Conference on Control and Systems, Amman, Jordan, pp. 117-212; 2002. 
[3] Burnfield JM, Shu Y, Buster TW, Taylor AP, McBride MM, Krause ME. Kinematic and electromyographic analyses of normal and device-assisted sit-tostand transfers. Gait \& posture. 2012; 36(3): 516-22.

[4] Frost DM, Abdoli-EM, Stevenson JM. PLAD (personal lift assistive device) stiffness affects the lumbar flexion/extension moment and the posterior chain EMG during symmetrical lifting tasks. Journal of Electromyography and Kinesiology. 2009; 19(6): 403-12.

[5] Gupta AK, Arora SK. World-class warehousing and material handling. Industrial automation and robotics. New Delhi: Laxmi Publication; 2009.

[6] Keir PJ, MacDonell CW. Muscle activity during patient transfers: a preliminary study on the influence of lift assists and experience. Ergonomics. 2004; 47(3):296306.

[7] Zhang W, Zhang C, Zhao J, Du C. A Study on the Static Stability of Scissor Lift. The Open Mechanical Engineering Journal. 2015: 954-60.

[8] Horino S. Environmental factors and work performance of foundry workers. Journal of human ergology. 1977; 6(2): 159-66.

[9] Corrado A, Polini W, Canale L, Cavaliere C. To design a belt drive scissor lifting table. International Journal of Engineering and Technology. 2016; 8(1): 515-525.

[10] Majewski M, Kacalak W. Smart control of lifting devices using patterns and antipatterns. In Computer Science On-line Conference, pp. 486-493; 2017.

[11] Miądlicki K, Pajor M. Overview of user interfaces used in load lifting devices. International Journal of Scientific \& Engineering Research. 2015; 6(9):1215-20.

[12] Naito K, Kanno T, Miyazaki T, Kawashima K. Development of minimally invasive lifting device using extension and flexion of pneumatic soft actuator for laparoscopic surgery. InSystem Integration (SII), 2017 IEEE/SICE International Symposium, pp. 565-570; 2017.

[13] Campeau-Lecours A, Foucault S, Laliberté T, Mayer-St-Onge B, Gosselin C. A cable-suspended intelligent crane assist device for the intuitive manipulation of large payloads. 2016; 21(4): 2073-2084.

[14] Flores-Morán E, Yánez-Pazmiño W, Barzola-Monteses J. Genetic algorithm and fuzzy self-tuning PID for DC motor position controllers. In 19th International Carpathian Control Conference (ICCC), pp. 162-168; 2018.

[15] Haselsteiner AF, Ohlendorf JH, Oelker S, Ströer L, Thoben KD, Wiedemann K, De Ridder E, Lehmann S. Lifting wind turbine components from a floating vessel: A review on current solutions and open problems. In ASME 2018 37th International Conference on Ocean, Offshore and Arctic Engineering, pp. 17-117; 2018.

[16] Kulak O. A decision support system for fuzzy multi-attribute selection of material handling equipment. Expert systems with applications. 2005; 29(2): 310-9.

[17] Williams T. Fuzzy logic simplify complex control problems. Computer design. 1991: 90-102.

[18] Mamdani EH. Application of fuzzy logic to approximate reasoning using linguistic synthesis. In: 6th Proceedings of the symposium on Multiple-valued logic, pp. 196-202; 1976.

[19] Elias N, Yahya NM, Sing EH. Numerical Analysis of Fuzzy Logic Temperature and Humidity Control System in Pharmaceutical Warehouse Using MATLAB Fuzzy Toolbox. In: Hassan MHA, editors. Intelligent Manufacturing \& Mechatronics. Singapore: Springer Singapore; 2018: 623-629. 
[20] Islam MS, Mir S, Sebastian T. Issues in reducing the cogging torque of massproduced permanent-magnet brushless DC motor. IEEE Transactions on Industry Applications. 2004; 40(3): 813-20. 